\title{
O ÍNDICO, UMA PROMESSA DE HORIZONTE - ENTREVISTA COM JOÃO PAULO BORGES COELHO
}

THE INDIAN OCEAN, A PROMISE OF HORIZON INTERVIEW WITH JOÃO PAULO BORGES COELHO

Elena Brugioni Gabriela Beduchi Zanfelice

Professora de Literaturas Comparadas no Departamento de Teoria Literária do Instituto de Estudos da Linguagem (IEL) da Unicamp.

Aluna do curso de Graduação em Letras no Instituto de Estudos da Linguagem (IEL) da Unicamp.

Via Atlântica, Săo Paulo, n. 38, pp. 437-469, dez. 2020. 
Resumo: João Paulo Borges Coelho é professor, historiador e escritor moçambicano de grande destaque no âmbito das Literaturas Africanas em língua portuguesa. A seguinte entrevista a João Paulo Borges Coelho foi realizada em Oxford, em novembro de 2019, e posteriormente revista e editada em colaboração com Elena Brugioni. Motivada pelos objetivos de propor o Oceano Índico e a Literatura-Mundial como possíveis paradigmas críticos para o estudo das Literaturas Africanas e de analisar os contos de Índicos Indícios (Borges Coelho, 2005) como narrativas emblemáticas de imaginários transnacionais da contemporaneidade moçambicana, a entrevista aborda, entre outras, questões referentes às relações entre literatura e crítica literária, África e o mar, Moçambique e o Índico, bem como algumas reflexões do autor sobre narrativas históricas.

Palavras-chave: literaturas africanas, Oceano Índico, Moçambique, Literatura-mundial, João Paulo Borges Coelho. 
Abstract: João Paulo Borges Coelho is a mozambican professor, historian and writer of great prominence in the context of the portuguese-speaking African Literatures. The following interview with João Paulo Borges Coelho was carried out in Oxford, November 2019, and subsequently reviewed and edited in colaboration with Elena Brugioni Motivated by the objectives of proposing the Indian Ocean and World-Literature as potential critical paradigms for the study of African Literatures and of analysing the short-story books Índicos Indícios (Borges Coelho, 2005) as emblematic narratives of Mozambique's transnational imaginaries, this interview addresses, among others, questions concerning the relations between literature and literary critique, Africa and the sea, Mozambique and the Indian Ocean, as well as Borges Coelho's reflections on historical narratives.

Keywords: African Literatures, Indian Ocean, Mozambique, world-literature, João Paulo Borges Coelho. 
João Paulo Borges Coelho é professor, historiador e escritor moçambicano de grande destaque no âmbito das Literaturas Africanas em língua portuguesa. Seu projeto conta com catorze obras publicadas e abrange diversos gêneros literários, como história em quadrinhos, contos, novelas e romances, para além de uma produção acadêmica significativa decorrente de sua carreira como historiador. 0 pensamento crítico que se debruça sobre a obra literária do autor não só demonstra ser expressivo até o momento como cresce significativamente, sobretudo no Brasil, onde acaba de ser publicado, pela Editora Kapulana, o livro As Visitas do Dr. Valdez (2019). Observando a fortuna crítica da obra de Borges Coelho, vale frisar um aumento significativo das pesquisas acadêmicas, de diversos níveis, no campo dos estudos literários dentro e fora do Brasil sobre seu projeto literário, bem como a publicação de ensaios e coletâneas, em português e em outras línguas, integralmente dedicadas à sua obra. ${ }^{1}$ Trata-se, em suma, de um autor que apesar da sua recente estreia literária, com a primeira obra publicada em 2003, tem despertando um interesse crescente no campo dos estudos literários e da crítica às literaturas africanas contemporâneas.

A presente entrevista foi realizada presencialmente em Oxford, em novembro de 2019, e posteriormente revista e editada em colaboração com a Professora

1 A este respeito, veja-se, por exemplo, Khan et al. (2017), Can (2014) e Brugioni et al. (2020). 
Elena Brugioni após meu regresso ao Brasil. A entrevista se insere nas pesquisas desenvolvidas no âmbito do projeto de Iniciação Científica "Territorializando o Índico. Imaginários Transnacionais e Literatura-Mundial em João Paulo Borges Coelho", atualmente em curso na Universidade Estadual de Campinas sob a orientação da Prof. ${ }^{a}$ Dr. ${ }^{\text {a }}$ Elena Brugioni e financiado pela Fundação de Amparo à Pesquisa do Estado de São Paulo, FAPESP (Ref. 2018/20953-6). No âmbito do projeto, realizei um estágio de pesquisa na Universidade de Warwick, Inglaterra, onde tive a oportunidade de entrevistar o autor que se encontrava no país por ocasião de uma série de palestras que havia de ministrar na Universidade de Oxford e noutras universidades do Reino Unido. Motivada pelos objetivos da pesquisa em propor o Oceano Índico e a Literatura-Mundial como possíveis paradigmas críticos para o estudo das Literaturas Africanas e para a análise da obra Índicos Indícios (Borges Coelho, 2005) como narrativas emblemáticas de imaginários transnacionais não essencialistas acerca da modernidade e da contemporaneidade moçambicana, a entrevista aborda, entre outras, questões referentes às relações entre literatura e crítica literária, África e o mar, Moçambique e o Índico, bem como algumas reflexões do autor sobre narrativas históricas. 


\section{Elena Brugioni, Gabriela Beduchi Zanfelice (EB,}

GBZ) $A$ inserção da sua obra no âmbito das Literaturas do Índico e da Literatura-Mundial proporciona a possibilidade de uma ruptura com os parâmetros de classificação literária pautados pelo estado-nação, convidando o olhar do leitor a caminhar em direção a quadros mais amplos. Você conhece o debate acerca da Literatura Mundial e a perspectiva proposta pelo Warwick Research Collective (WREC)?

João Paulo (JP): Ouvi falar em Weltliteratur, mas essa perspectiva específica não conheço.

\section{EB, GBZ: O Warwick Research Collective (WReC) ${ }^{2}$} apresenta um comprometimento materialista para com a Literatura-Mundial. A proposta do coletivo é entender a literatura-mundial como toda a literatura surgida no sistema-mundial capitalista moderno. Assim, a partir do século XVI, toda a literatura é considerada literatura-mundial porque ela registra, de forma consciente ou não, as contradições e condi-

2 O Coletivo de Pesquisa da Universidade de Warwick (WReC), formado em 2007, apresenta uma agenda de pesquisa baseada no desafio de teorizar um sistema-mundo-literário que é, nas palavras de Franco Moretti (2000), simultaneamente uno e desigual, a partir de um comprometimento materialista para com as implicações culturais das teorias do desenvolvimento desigual e combinado. 0 grupo é formado por professores de diversos campos teóricos da Universidade de Warwick e publicou, em 2015, o livro Combined and Uneven Development: Towards a New Theory of World-Literature, onde estabelecem seus principais argumentos. A tradução da obra para o português encontra-se em vias de publicação pela Editora da Unicamp. 
ções materiais desse sistema capitalista. Como você encara esta proposta?

JP: Eu não trabalho com a teoria da literatura, da interpretação, da crítica. É um mundo que só indiretamente conheço. Trabalho do ponto de vista da produção literária, e os conceitos que trago não são conceitos de coordenação de leituras, mas são conceitos operacionais, ou seja, conceitos que construo para me posicionar e dar um sentido à minha prática; o que é diferente, portanto. Essa é a primeira ressalva. A segunda, e que pra mim é muito importante, é que nessa prática há uma componente inteligível e uma componente emocional, ou intuitiva, que eu não quero matar. Isso é uma grande diferença em relação ao trabalho acadêmico. 0 trabalho acadêmico tem parâmetros, paradigmas e metodologias, enquanto o trabalho de escrita é muito mais livre, segue a intuição. Também segue parâmetros, é claro, éticos, estéticos, mas segue forças misteriosas que eu não quero sequer descodificar porque temo que, ao descodificar, vou matar o que me interessa procurar aí: um espaço de libertação, de sinestesia, as ligações com a música, tudo isso. Portanto essas são as duas grandes ressalvas ou pontos de partida com os quais quero começar. Depois, para mim é muito interessante a perspectiva da Weltiteratur porque eu acho que o campo é um campo só. Grande parte dos estudos literários partem de dois princípios que são, para 
mim, muito preocupantes. 0 primeiro, mais real, é o princípio de que através da ficção ou da literatura se podem explicar as sociedades, como se elas fossem mais uma chave de uma antropologia ou de uma sociologia. Isto sobretudo nos países do terceiro mundo: a literatura ajuda a explicar. E não sei se isso é verdade. Ajuda em partes, mas não é uma chave da explicação porque é, ao mesmo tempo, uma fuga da explicação. E o principal elo de ligação da literatura com o leitor não é o de ajudar a interpretar outra coisa, é o da fruição através da leitura. Não sei se é clara esta ideia, mas para mim é muito central. A outra é que isso perverte o ambiente literário quando ele não é forte. Mesmo aqui, por exemplo, escritores com lugar assegurado no mercado afeiçoam-se à crítica e às interpretações. E muito mais lá, onde os escritores são muito mais vulneráveis. Tende a haver uma ligação perversa com os estudos literários, no sentido em que estes usam os textos para compreender a sociedade e os escritores afeiçoam-se a essa perspectiva, tentam corresponder ao que é dito. E isso perverte todo o jogo. 0 espaço do escritor é totalmente independente do espaço de quem interpreta. Por isso, tudo o que quiseres dizer acerca dos Índicos Indícios, ${ }^{3}$ por exemplo, eu acho legítimo, não tem que passar sobre o meu crivo, porque é o

3 BORGES COELHO, João Paulo. Índicos Indícios: Setentrião (2005a) e Índicos Indícios: Meridião (2005b). 
teu trabalho, não é o meu. 0 meu trabalho esgotou-se ali, naquele diálogo. 0 teu trabalho é um outro, que segue regras, critérios, interesses, e que segue emoções, também, intuições. Mas isto por um lado. Por outro lado, voltando à ideia da Weltliteratur, pra mim é muito interessante esse espaço sem barreiras porque a prática a que eu vinha a referir torna mais cômodo - talvez por preguiça - definir os espaços de acordo com fronteiras políticas. Podem até ser fronteiras culturais, mas são basicamente políticas. "Eu especializo-me na literatura moçambicana”, como se a literatura moçambicana fosse um dado. Quando não é, está a surgir. Quando se fala em literatura americana ou literatura austríaca, normalmente, não tem-se apenas uma definição das fronteiras políticas, mas uma definição de correntes estéticas que se criaram e que caracterizam esses movimentos, e que por comodidade se chama americana ou austríaca. Mas são lógicas, chega-se a essa categoria através de uma sedimentação de muito material. No caso de Moçambique ou da Angola, por exemplo, não há tanto material assim e está-se a transformar aquilo que deve ser uma coisa post facto numa coisa ante facto. Ou seja, define-se à partida. Então pode dar azo a todo um conjunto de discussões, algumas até absurdas. Em Moçambique houve muito a discussão “o que é um escritor moçambicano?". Eu não estou minimamente interessado nessa discussão. A mim, 
intriga-me: numa literatura tão jovem, não é muito saudável falar dum coletivo. E não se discutem as obras, discutem-se muito menos as obras. Quem discute as obras está fora, normalmente. Agora voltando, mais uma vez, à Weltliteratur, a mim é também interessante porque a literatura moçambicana está a surgir sobre uma grande pressão do paradigma nacionalista. Como se fosse o nacionalismo que desse sentido à literatura. A literatura traduz, à sua própria maneira, o mundo, não traduz nenhum aspecto do mundo. Portanto, tudo o que seja no sentido de libertar dessa camisa de forças - e eu não sou nacionalista, mas isso não é combater o nacionalismo - é defender uma literatura que seja dona do seu próprio nariz, que seja uma prática autônoma. Isto em relação ao conceito da literatura. Agora, aos espaços determinados pela literatura-mundo, é claro que é estranho quando tu chegas, por exemplo, à FNAC em Lisboa e tens "Literatura Portuguesa”, "Literatura Inglesa” e, depois, num cantinho, "Literatura Africana”. Este jogo perverso, que é o jogo da excepcionalidade, é um jogo procurado pelos estudos literários, uma armadilha em que os autores caem quando procuram também o espaço de excepcionalidade. Quando o jogo deve ser sempre ambíguo na aspiração do universal, mas com os pés na terra do local. Há sempre este trânsito do sentido. Porque tu podes escrever sem ter uma ligação com o sítio onde estás, acho 
perfeitamente legítimo. Há aquele exemplo do Xavier de Maistre que escreve à volta do quarto, ou o exemplo, até mais louco, daquele Raymond Roussel, que escreveu um livro sobre África que não tem nada a ver com África, é totalmente delirante, Impressões da África, ${ }^{4}$ e depois escreveu outro, Novas Impressões da África, ${ }^{5}$ com reis inventados e animais completamente out of the blue. Acho isso legítimo. Mas da maneira como vejo a prática, tento interpretar o meu mundo de uma forma em que o meu mundo é o mundo inteiro - não é nenhum lugar, é o mundo inteiro. Neste sentido, acho que faz bem ao mundo e faz bem à África, também, quebrar esta excepcionalidade. Infelizmente há muitos equívocos a este respeito. Há equívocos que resultam, por exemplo, da raça. A afirmação da raça é um fenômeno, ou um momento importante na luta pela igualdade, mas também traz esse outro lado da moeda que é exatamente o de acentuar a excepcionalidade. E acentuar a excepcionalidade é acentuar a diferença. Portanto é um bocado contraditório, neste respeito.

Depois, a literatura é omnívora. Ela fabrica a sua própria teia, mas alimenta-se de tudo. Não é só a academia que se alimenta da literatura, a literatura alimenta-se da realidade. E o meu tema sobre o mar tem a ver com isso. Por um lado, tendo a uma po-

4 ROUSSEL, Raymond. Impressions d'Afrique (2011).

5 ROUSSEL, Raymond. Nouvelles Impressions d'Afrique (2004). 
sição cada vez mais radical em relação ao mar, um pouco como o conceito ou metáfora do coral proposta pelo poeta mauriciano Khal Torabully. ${ }^{6}$ Para ele, a substância do coral transmite melhor a identidade. Partindo do conceito de redes de Deleuze e Guattari, ele afirma a maneira diferenciada sob a qual o coral se desenvolve. Já encontrei esse poeta nalguns sítios, alguns até absurdos - e eu gosto da situação do absurdo. Um deles foi em Barcelona, quando três departamentos, um de português, um de inglês e um de francês, fizeram um evento sobre o Índico. Chamaram Indícios e trouxeram a mim do departamento de português, um escritor tanzaniano que escreve em inglês [Abdulrazak Gurnah] e a Ananda Devi, escritora das Maurícias, que escreve em Francês. Me diverti muito, porque eu era o único branco, mas que vinha da África (risos). A Ananda Devi vive em Zurich e o escritor da Tanzânia vive em Londres. Então criou-se esta situação ambígua, que era interessante à sua maneira. Mas o ponto em que eu queria chegar era: o Índico criou culturas mais do que criou uma cultura. 0 Índico, com as travessias, deu cores diferentes ao caráter homogêneo e compacto de cada uma de suas margens, misturou. Neste sentido é muito interessante, mas também tem algumas armadilhas. Uma delas é a de, atualmente, os estudos literários caírem na

6 TORABULLY, Khal. Chair corail, fragments coolies: poésie. (1999). 
tentação de ver o Índico como um espaço de travessias. Há poucas travessias hoje. Para dar uma ideia, uma vez fui à Madagascar e foi um problema para arranjar o visto. Havia um cônsul lá que dizia: "Há seis meses que ninguém pede um visto para ir à Madagascar de Moçambique!”. E há um canal só no meio, ou seja, não há ligações. Me surpreendeu um bocado.

Outra vez, organizei um evento sobre a segurança marítima do Índico e veio um capitão de mar-e-guerra malgaxe à Moçambique e contou-me (o que depois eu vi, de fato, em Madagascar) que a África é uma coisa distante para eles. Ele dizia: "As elites daqui passam muito as férias nas Fiji e na Nova Zelândia. As Fiji têm coisas em comum conosco". Fiquei surpreendidíssimo com isso. Há um mar imenso e eles estão ali perto. Ou seja, historicamente há uma pequena bolsa que tem origem em Moçambique por conta do comércio de escravos para o trabalho nas plantações, assim como há bolsas de descendentes de mauricianos que vieram trabalhar no açúcar em Moçambique. Mas, presentemente, as ligações são muito mais frágeis, feitas a nível de estado, e não a nível cultural e comunitário. Há, por exemplo, uma forte componente de influência da cultura de Goa em Moçambique, mas é uma componente passada. Hoje não há tanta ligação. Os próprios goeses perdem ligação com a sua terra. Não é que não existam coisas, mas é uma 
nota de caução para não transformarmos a realidade numa espécie de wishful thinking que responda às construções que fazemos.

EB, GBZ: Ao longo de todos os contos de Índicos Indícios, o mar é um tema central, e me lembro do senhor ter afirmado em entrevista anterior que um moçambicano pode ter muito mais em comum com um camponês da Tanzânia do que com alguém propriamente moçambicano. Tendo em vista esta ausência de ligações atuais pelo Índico que acabou de comentar, como podemos entender estas relações? 0 que motiva a inserção do mar em sua literatura?

JP: São dois modelos. Um modelo cultural e um modelo político moderno do pós-Segunda Guerra, do pós-independências, que define fronteiras que de fato dividem comunidades. Eu tenho uma ligação emocional grande porque, da parte da minha mãe, descendo de ligações das Maurícias. A minha mãe nasceu no Ibo, numa pequenina ilha, minha avó nasceu no Ibo, minha bisavó e minha trisavó nasceram no Ibo. Portanto tenho uma ligação muito forte ali. Depois, toda a minha vida eu vivi a cem metros do mar. Mas em termos mais prosaicos, a origem do livro está em que nós [o autor e sua família] fizemos uma grande viagem até o Ibo de carro — são dois mil e quinhentos, quase três mil quilômetros - e depois viemos pela costa a descer. Então é um bocado de fragmentos que fui apanhando a par- 
tir daí. A ideia central também é esta oposição: eu conheço bem o interior, o Zimbábue, etc., e vejo a importância, de facto, que o mar dá em termos de perspectiva e de abertura do espaço, contra aquela ruralidade dos estados do interior, que não têm o mar no horizonte. Qual é a substância daquelas culturas marítimas? 0 que é que a água traz, neste aspecto, de diferente? Tenho um livro mais recente, elaboração ficcional em cima da memória, que é o Ponta $\mathrm{Gea}^{7}{ }^{7}$ em que isso é talvez também mais patente ainda: a importância do mar. Hoje eu evoluiria ainda para uma posição mais radical talvez, em que não é só o mar que é visto a partir da terra, mas como é que a terra é vista a partir do mar? Isto é ir mais longe um pouco, é ir de fato a caminho da liberdade e da ficção. No mar não há itinerários. Faz-se um itinerário e ele apaga-se, pode-se começar de novo. É um calabouço perfeito. Claro que há poluição, os mares de plástico, os submarinos, as plataformas offshore de petróleo e tudo isso. Mas o mar é muito mais constante que a terra. Lembro-me, por exemplo, fiquei muitos anos sem ir à Beira, que é o meu lugar. Muitos anos, décadas, quase quarenta anos. Eu tinha medo de ir à Beira porque era um sítio do passado. Quando conhecia bem o resto do país, voltei lá e tive alguma conexão com os espaços. Com calçada em que, quando crianças, fizemos riscos no cimento. Hoje chegamos lá quase

7 BORGES COELHO, João Paulo. Ponta Gea (2017). 
cinquenta anos depois e estão lá aqueles riscos. E ninguém sabe daqueles riscos. É como se houvesse um pacto secreto que passou despercebido a toda a gente. Portanto há esses pontos, mas há também a estranheza a uma cidade que é hoje uma ocupação diferente, desvirtuou daqueles traços originais, criou outros traços. Mas sentando nos mesmos lugares e olhando para o mar, é o mesmo mar que está lá, com as mesmas luzes que havia na infância. 0 mar é igual. 0 resto, tudo mudou. Neste sentido, o mar é uma espécie de último ponto a que nós nos podemos agarrar agora que o mundo está a acabar, que a natureza está a acabar. Talvez seja um bocado delirante, mas para mim esta ideia é importante. Porque por toda a parte tens traços do ocaso da natureza. São as árvores que não crescem, os animais que se extinguem, os frutos que já não há... Não sei até quando vamos poder ignorar esses sinais. Extinguem-se as línguas, extinguem-se os animais, extinguem-se... Dizem que neste século vai deixar de haver países no mar. Mas, por enquanto, a coisa mais constante que temos é o mar. Durante muito tempo eu tinha complexo com essa perspectiva, porque parece uma perspectiva conservadora. Mas não é uma perspectiva conservadora, é a de tentar descobrir novas relações com a natureza. Não é uma perspectiva conservadora: é um grito de alerta contra a perspectiva conservadora que é a 
de continuar, a esta velocidade, a destruir o mundo sem propósito, só por inércia.

\section{EB, GBZ: Pelo suposto progresso...}

JP: Exatamente. E por inércia e irresponsabilidade, porque há enormes, abissais avanços, mas ao mesmo tempo há uma grande irresponsabilidade social. 0 Facebook, por exemplo, que era uma promessa de ligação das pessoas, não tem minimamente em conta o impacto social que ele tem sobre as relações entre elas. Portanto isso é que é conservadorismo irresponsável. Mas já estou a fugir das tuas indagações. É toda a volta do mar. (risos)

EB, GBZ: Há um historiador do Índico, Michael Pearson, que também argumenta que os estudos marítimos não deveriam apenas expandir as categorias historiográficas pensadas primordialmente para o continente, mas deveriam ver a história do continente a partir do mar, sugerir categorias novas, alternativas. Ele trabalha na direção de inserir África no sistema do Índico. E isso vai no sentido contrário às perspectivas que analisam Moçambique apenas pelas conexões do Atlântico, que acontecem especialmente no Brasil, esquecendo que ele na verdade está no Índico. Em um de seus livros, ${ }^{8}$ Pearson cita Malyn Newitt, que afirma que o vale do Zambeze é,

8 PEARSON, Michael. The Indian Ocean (2007). 
de muitas maneiras, uma extensão da zona costeira. Concorda com estas perspectivas?

JP: Sim. Sem dúvida, o perfil de Moçambique é do Índico. 0 vale do Zambeze foi todo ele ocupado por uma ordem colonial cuja ponta da lança era, em grande medida, goesa, porque Portugal não tinha gente nem meios. Então houve um sistema de prazos ao longo do rio [Zambeze] e houve muitos senhores goeses e afro-goeses que representavam Portugal, mas que por longos períodos estavam contra Portugal. O Newitt traz as perspectivas mais interessantes sobre o Zambeze. Há um historiador americano, Allen Isaacman, que escreveu muito sobre isso, mas que elabora, às vezes, de maneira um bocado delirante. Mas a penetração até ao Botswana, onde o Zambeze sai e faz a divisão entre a Rodésia, atual Zimbábue, e a Zâmbia, até aí aonde entra em Moçambique, foi ocupado pelos senhores afro-goeses. Portanto, é uma longa distância da costa, e isso aconteceu em várias fases. Ou seja, essa entrada foi suportada por vários ciclos. Primeiro foi o ciclo do ouro no século XVI, a procura das minas de ouro no interior, depois o ciclo do marfim e, finalmente, o ciclo dos escravos. Chegaram escravos à costa de Moçambique, através do Zambeze, que vinham do Kazembe, quase na Angola. Portanto foi de fato uma penetração com grande cariz Índico e afro-goês. 
EB, GBZ: Concorda também com a classificação que Pearson faz de Sena e Tete como "cidades portuárias do interior" [inland port cities] ou "portos fluviais" [fluvial ports]?

JP: Sim. A maior parte do tráfico foi ao longo do Zambeze. Havia também rotas que iam para cima do Zambeze, porque Quelimane - embora não esteja na foz, porque aquilo é um delta muito vigoroso, sempre a mudar de direção - é uma cidade quase da foz do Zambeze e foi um grande entreposto de escravos nos séculos XVII e XVIII. Portanto Sena foi um porto importante nesta altura. Houve outros. Vai subindo até a Feira, que é uma cidade fronteiriça na Zâmbia e tem este nome de feira, de mercado, um nome português. Quando estive lá mostraram-me pedras com palavras portuguesas. Isso é muito interessante e foi incorporado aos valores locais. 0 meu primeiro livro, que se chama As Duas Sombras do Rio, ${ }^{10}$ é focado no Zambeze e vem duma experiência incrível que tive exatamente nessa zona do Zumbo, onde o Zambeze entra em Moçambique. Portanto é um ponto onde há três países, a Zâmbia, o Zimbabwe e Moçambique, todos num único ponto. Era muito interessante porque vinha o chefe da polícia Kanyemba (uma vilazinha do Zimbábue), de barco, passava em Bawa (uma pequena aldeia perto do Zumbo), onde eu estava, apanhava-me e ía-

9 Idem, p. 33.

10 BORGES COELHO, João Paulo. As Duas Sombras do Rio (2003). 
mos beber uma cerveja à Feira, que era na Zâmbia. Depois voltávamos devagar, para não acordar os hipopótamos, e ele deixava-me ali já com umas cervejas, e seguia lentamente de volta ao Zimbábue. E enquanto estive ali pude ver os espíritos goeses da Índia a circular. Pessoas com nomes portugueses, mas afro-goeses. Kanyemba e Matsekenya (Araújo Lobo), por exemplo, eram senhores de prazos afro-goeses, com esses nomes portugueses pomposos, mas que já tinham raízes porque incorporavam um sistema em que alguns mortos notáveis se transformam em espíritos que protegem a comunidade. E muitos destes espíritos eram afro-goeses. Portanto mostra uma integração profunda no sistema da organização social local.

EB, GBZ: Aproveitando a deixa do "sistema", qual a sua visão em relação ao modelo dos sistemas-mundo de Wallerstein ?11 $^{11}$

JP: Nossas primeiras chaves de interpretação eram e ainda são, de alguma maneira, anteriores ao Wallerstein, estavam ancoradas no André Gunder Frank, em nomes que hoje são pré-históricos, quase. 0 Wallerstein chegou já na altura da independência. Havia um centro importante em Maputo, o Centro de Estudos Africanos, que tinha uma componente, digamos, diplomática, que era o Aquino de Bragança, e uma componente de estudos sociais

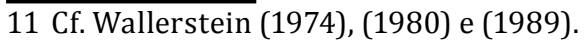


que era a Ruth First, que foi uma figura importante. 0 Aquino de Bragança tinha uma grande amplitude, foi ele que trouxe lá o Wallerstein. Essa foi a nossa altura de abertura. Foi a pequena janela pela qual grandes antropólogos e historiadores franceses como Claude Meillassoux, Pierre-Philippe Rey e Catherine Coquery-Vidrovich, por exemplo, chegaram a Moçambique. E também Yves Lacoste, importante geógrafo, que escreveu um livro que abria perspectivas, La géographie, ça sert, d'abord, à faire la guerre ["A geografia, isso serve, em primeiro lugar, para fazer a guerra"12]. Quer dizer, isto era gente que foi dar aulas lá quando éramos estudantes, porque Moçambique estava na moda, fazia uma revolução com sabor internacional, internacionalista. Então essa gente ia lá para conhecer. O Jean Luc-Godard foi lá por causa do cinema, o Jean Rouch, outro cineasta-historiador importante, também. Tudo isso fez daquilo um movimento cultural muito grande. Era como o mundo estava antes de voltar a fechar, porque foi perdendo essa componente. Criou-se uma matriz de visão internacionalista do mundo. 0 próprio marxismo, que está na base da nossa formação na altura, criou também. Embora o marxismo em relação à África e ao terceiro mundo tenha grandes discussões, muitos strings attached. Mas de qualquer forma deu-se essa visão interna-

12 LACOSTE, Yves. A geografia - isso serve, em primeiro lugar, para fazer a guerra (1988). 
cionalista, era o princípio das teorias do terceiro mundo, etc. Neste sentido, é essa a nossa cultura. É essa a nossa cultura acadêmica, de uma pequena ilha. E era a própria cultura da FRELIMO (Frente de Libertação de Moçambique) no início. O Aquino de Bragança foi um importante contribuidor de uma revista chamada Afrique-Asie, que tinha grandes raízes na Argélia revolucionária do Boumédiène do princípio, do Ben Bella, etc. Portanto a própria matriz da FRELIMO é internacionalista, porque os movimentos de libertação de Moçambique, da Angola e da Guiné - a Angola com o MPLA (Movimento Popular de Libertação de Angola) e a Guiné com o PAIGC (Partido Africano para a Independência da Guiné e Cabo Verde) - juntaram-se no antepassado. Não tem nada a ver com a CPLP (Comunidade dos Países de Língua Portuguesa), mas chamava-se CONCP, Confederação das Organizações Nacionalistas das Colônias Portuguesas, que foi criada em Marrocos. E muitos dos elementos do movimento nacionalista vinham de França, de Lisboa, etc., onde estudaram. Portanto havia esta matriz mundial, digamos assim. E a FRELIMO nunca se definiu, no princípio. Sempre jogou na ambiguidade, até dentro do movimento comunista, em relação à China e à União Soviética, enquanto outros movimentos nacionalistas, como o MPLA, normalmente tinham que fazer prova de lealdade a uma dessas potências. Moçambique sempre jogou nessa ambiguidade. Há 
até fotos da reunião do Eduardo Mondlane com o Che Guevara em 1961, quando o Che Guevara foi a Dar Es Salaam. Portanto há um passado internacionalista que se foi fechando no nacionalismo. 0 nacionalismo foi o preço a pagar para poder fazer a luta. Mas ficou talvez uma nostalgia desse traço de abertura que se foi fechando. E, de fato, o mundo explica-se no mundo. Para mim houve, de fato, uma fase braudeliana muito importante, em que a escala maior interpretava tudo. Continuo a acreditar que a grande escala explica, mas tenho uma curiosidade de como ligar ao local. Como é que se cria a articulação? Talvez um dos grandes sentidos da malese atual da globalização é não estarmos claros sobre como é que o local encaixa dentro desta suposta cultura universal, global. Esses problemas de ligação é que criam este refluxo, esta ressaca de nacionalismos exacerbados que está a surgir outra vez. Pelo menos é assim que eu vejo.

EB, GBZ: A ressalva que fez anteriormente em relação às ligações do Índico é importante para tomarmos cuidado em não ver a literatura como uma mera reflexão da realidade, para não confundirmos a literatura com a história. Em diversas palestras, o senhor menciona a obra de Walter Benjamin. Sendo historiador, como encara as teses de Benjamin sobre o conceito de História, as vê principalmente como um 
documento da sua época (1940) ou vê a possibilidade de continuar a intervir no mundo hoje ${ }^{13}$

JP: Para mim o Benjamin é uma fonte de inspiração, regresso sempre ao Benjamin. Agora estou a regressar ao colecionador, ao Benjamin das coleções. É uma espécie de "quais são os restos que ficam depois de esvaziados de tempo?". E o tempo é o sentido. Ficam as coleções, que resumem o completo e a fragmentação do mundo. ${ }^{14} 0$ Benjamin é uma leitura muito difícil, mas ao mesmo tempo é uma leitura muito inspiradora. Eu acho, de longe, o mais revolucionário dos historiadores. 0 mais revolucionário dos históricos. Ultimamente, não sei se havia uma celebração em relação a alguma efeméride relacionada ao Adorno, com a escola de Frankfurt. Até em Moçambique houve um colóquio sobre o Adorno, e [do Benjamin] ninguém fala. Quer dizer, o Benjamin é sempre uma figura da margem, uma figura meio misteriosa, mas uma figura muito iluminadora. É um revolucionário, no sentido mais fundo. Por falar nisso, há um livro muito interessante de ensaios da Beatriz Sarlo sobre o Benjamin. ${ }^{15}$ No fundo o Benjamin é sempre incompleto, mas abre sempre as janelas. Não é uma literatura morta. Acho que é, mais do que nunca, uma litera-

13 Agradeço ao Professor Paulo de Medeiros pela sugestão do tópico desta questão.

14 Cf. Benjamin (1989), (1987) e (2013).

15 SARLO, Beatriz. Sete ensaios sobre Walter Benjamin e um lampejo (2013). 
tura viva. Ele faz, talvez, um pouco aquilo que faz o Ginzburg - e eu recorro muitas vezes a essa imagem - que é o estranhamento do mundo. ${ }^{16} \mathrm{Ou}$ seja, dá um passo atrás e olha para as coisas como se estivesse a ver pela primeira vez, o que é o gesto da criança, da descoberta. Nós não vemos quando não paramos e damos um passo atrás para estranhar o mundo, para depois voltar a entrar nele.

EB, GBZ: Que imaginários você acha que o Índico pode sugerir na construção da modernidade moçambicana e qual o papel de Moçambique neste sistema do Índico? Como ele se integra nesse sistema, para além das motivações pessoais que levaram à escrita do livro?

JP: Em primeiro lugar, o mar começa por ser maldito em África. Não há uma tradição africana de mar. Enquanto no Brasil, por exemplo, para grande parte da população de origem africana o mar é o caminho de regresso, de chegar às origens, de Iemanjá, etc. Mesmo para os afro-americanos, a origem está em África através do mar. Visto a partir da África é o contrário: o mar é o vazio que engoliu as pessoas. Os escravos que de lá saíram, desapareceram no mar. Isso faz toda a diferença. Este é um sentimento que depois foi ainda mais acentuado pela subalternidade colonial. Não há uma tradição de mar. Há a pesca, mas é uma pesca costeira, de pequenas ca16 Sobre o conceito de estranhamento do mundo, cf. Ginzburg (1989) e (2001). 
noas. No caso de Moçambique o movimento de libertação é um movimento de matriz rural e de interior, que é onde se deu o combate. Nunca teve uma especial apetência para o mar. Nunca houve grande guerra junto do mar, foi tudo no interior. Após a independência, apesar de o camarão ter chegado a ser um dos principais produtos de exportação e da economia nacional, nunca houve uma discussão profunda sobre o mar, nunca houve uma estratégia marítima, nunca houve cabotagem, navegação costeira, etc. E depois, quando se criou a SADC (Comunidade para o Desenvolvimento da África Austral), quem define a atitude em relação ao mar é a África do Sul, que é a única que tem meios, a única que tem um projeto de economia azul e a única que tem barcos. Moçambique não tem nada. E inclusivamente, quando se criou alguma coisa sobre o mar, houve o escândalo de corrupção de desvio em Moçambique. Um conluio mafioso que desviou 2.5 bilhões de dólares da economia ilegalmente para a corrupção. É um processo muito complexo que abalou e provocou uma crise profunda que vivemos hoje em termos de economia. Mas é também um trauma. A primeira vez que se fala em mar, acontece isto. Porque a ligação [entre o escândalo de corrupção e o mar] é que era para comprar barcos de pesca de atum e para comprar barcos de segurança marítima da costa. Então, compraram-se vinte barcos de má qualidade, que custaram abaixo de duzentos 
milhões de dólares, mais seis lanchas de segurança e tudo isso justificou o desvio de 2.5 bilhões de dólares. No fundo é uma dívida que levou ao corte com o Banco Mundial, ao corte da ajuda de muitos países. E agora estamos a tentar recuperar disso. Ou seja, é um trauma que nos afasta ainda mais do mar, porque o mar significou corrupção. E um trauma que é trágico, porque veio numa altura em que se descobriam grandes reservas de gás offshore no mar, que estão a começar a ser exploradas. Portanto há toda esta contradição. Mas isto para dizer que, entretanto, o Índico evoluiu. Quer dizer, o Índico da Guerra Fria, que era um Índico norte-americano e russo, transformou-se num Índico multipolar, por um breve espaço, onde pontificaram os Estados Unidos, mas os próprios Estados Unidos foram tornando mais modesta a sua presença e o Índico está cada vez mais a tornar-se numa zona de conflito bipolar outra vez, de conflito entre dois grandes interesses: os chineses, com aquele projeto antigo do colar de pérolas e que é agora o do Belt and Road, que é a ligação de todo o espaço através do Índico, em competição com os indianos, com a Índia que tem uma vocação também hegemônica no Oceano Índico. A África do Sul lidera essa integração. Criou-se a coisa dos BRICS (Brasil, Rússia, Índia, China e África do Sul), que não é tão visível agora como era no passado. De qualquer maneira, a África do Sul é o único interlocutor ali. Do ponto de 
vista da presença internacional, Moçambique tem muito pouca visibilidade porque não tem, a meu ver, uma política clara. E vai ter que ter cada vez mais porque tem interesses econômicos que estão localizados no Índico. De tal forma que a partir de 2010, por exemplo, quando houve pirataria somali, começou a espalhar-se para o sul um mar de sul-africanos, que subiu toda a costa de Moçambique e foi posto em permanência em Cabo Delgado para fazer a segurança marítima porque Moçambique não tinha meios. Portanto, não tendo meios, nem política, nem perspectiva, não tem voz. É sempre uma posição subalterna em relação ao Índico.

EB, GBZ: Isso em termos econômicos e políticos governamentais. A nível da população e do cotidiano dos habitantes da costa, como se dá essa visão do Índico? JP: Essa visão acaba no chamado mar territorial. Em termos do direito internacional marítimo, a costa tem 20 milhas que são como se fossem terra. Tudo o que acontece lá é como se acontecesse em terra. Além disso, tem 200 milhas que são a zona econômica exclusiva - uma zona econômica internacional, mas que o país tem direitos de zelar pela segurança do tráfego marítimo, pela segurança da natureza, da poluição, etc. Mas que já é espaço internacional. Depois disso, só acordos especiais é que permitem a extensão da presença nacional. Eu diria que toda a relação do mar com Moçambique 
se esgota no mar territorial, naquele espaço pertinho da costa onde há uma pesca, porque para lá disso, tradicionalmente, desde a independência, quem pesca são navios espanhóis, japoneses, e agora chineses. Moçambique tem a costa a ser depauperada sem meios sequer para intervir. Não tem meios de localização da pesca clandestina, não tem presença. Tem muito escassa presença no mar. Portanto, mesmo para as comunidades costeiras o mar é o mar do pequeno pescador, que é muito importante, porque o peixe - há uma espécie de peixe, de nome científico Hilsa Khelee, que é uma espécie de sardinha africana pequena - ainda hoje é a maior fonte de proteína de toda a costa oriental de África. Há, depois, pequenos negócios entre o interior e a costa que tem a ver com esta pequena pesca. Mas ao mesmo tempo é também uma zona de conflito. Por exemplo, neste momento arrasta-se um conflito sério porque há pescadores da Tanzânia no Norte, que tem um sistema mais avançado, com barcos de maior calibre, que chegam para pescar em águas moçambicanas e os pescadores locais dizem que estão a ficar sem peixe porque os outros vêm por fora pescar - e isso tudo dentro da zona de costa. E eles nem falam das zonas mais distantes, onde há verdadeiros barcos-fábrica. São barcos que pescam, processam e exportam o peixe sem ligação com a terra. Quer dizer, há proximida- 
de e há distância ao mesmo tempo, há uma grande contradição.

Mas voltando aos Índicos Indícios, talvez o projeto era: como é que é sentida a devasta, como se manifesta dentro deste caso? 0 que é que ela provoca em termos de transformação identitária, qual é a importância deste elemento na construção da identidade costeira? E o Ponta Gea é: como é que essa mesma influência se manifesta num só lugar? Senti necessidade de voltar a um dos lugares. Tanto que uma das histórias dos Índicos Indícios é o Grande Hotel, que é um grande símbolo. E eu voltei outra vez a ele de uma outra maneira.

EB, GBZ: Sei que você tem essa consciência de que o autor não deve impor a leitura sobre a sua própria obra. Mas se fosse dar uma opinião sobre ela, quais os significados do Oceano Índico oferecidos pela sua obra? Que tipo de imaginário, possibilidades narrativas e conceitos o Índico - como lugar imaginário e geográfico - sua obra possibilita?

JP: Isso é muito geral, não é? (risos). É falar sobre o que já foi dito por escrito. Para mim, basicamente, o Índico é uma fonte. É uma fonte de energia. Sou um cozinheiro, gosto muito de cozinhar, e a matriz da minha cozinha é indo-mediterrânica. 0 Mediterrâneo, apesar de ser um mar quase morto, também é uma fonte de energia, às vezes. Mas o Índico é o meu mar. $\mathrm{Eu}$ não elaboro sobre ele. Eu procuro relaxar para 
que ele elabore sobre mim. Não quero domesticar o Índico, quero sentir a presença do Índico. Porque, no fundo, quem faz ficção é quem não consegue fazer poesia. Poesia é que é a arte superior. E, de fato, a poesia não interpreta, mas entra em conexão com a natureza, com as ideias. É isso o que eu procuro mais em relação ao Índico: que ele esteja presente, que seja uma espécie de anjo protetor. Muito mais do que tentar domesticá-lo, tentar elaborar e tê-lo numa caixa de explicações. É um pouco isso. Ele está presente naturalmente. Ele é mais amigável, apesar de sempre enfurecer. Mais amigável do que a terra. Neste sentido, é uma promessa de horizonte que está para lá das pessoas. Eu às vezes canso-me das pessoas. E outras vezes não. A literatura é acerca das pessoas. Mas os lugares englobam as pessoas, não são as pessoas que englobam os lugares. É como se os lugares estivessem lá, como se dessem a cor e o sentido às pessoas. Não sei bem como explicar. Mas é essa conexão com o mar e essa linha aberta que procuro para poder ouvir sempre, e para poder dizer o que me interessa em relação ao mar. Isso é a maritimidade que não consigo elaborar de uma outra maneira.

Agradecimentos: Agradecemos ao João Paulo Borges Coelho por ter nos concedido esta entrevista, ao Paulo de Medeiros pelo diálogo intelectual e a Phillip Rothwell pela organização do evento que permitiu a realização desta entrevista. 


\section{Referências}

BENJAMIN, Walter. Desempacotando minha biblioteca: Um discurso sobre o colecionador. In: BENJAMIN, Walter. Rua de mão única. São Paulo: Brasiliense, 1987 [1928].

BENJAMIN, Walter. Charles Baudelaire: um lírico no auge do capitalismo. São Paulo: Brasiliense, 1989 [1919].

BENJAMIN, Walter. Origem do drama trágico alemão. Belo Horizonte: Autêntica Editora, 2013 [1928].

BORGES COELHO, João Paulo. As Duas Sombras do Rio. Lisboa: Caminho, 2003.

BORGES COELHO, João Paulo. As Visitas do Dr. Valdez. São Paulo: Editora Kapulana, 2019 [2004].

BORGES COELHO, João Paulo. Ponta Gea. Lisboa: Caminho, 2017.

BORGES COELHO, João Paulo. Índicos Indícios I: Setentrião. Lisboa: Caminho, 2005a.

BORGES COELHO, João Paulo. Índicos Indícios II: Meridião. Lisboa: Caminho, 2005b.

BRUGIONI, Elena; GROSSEGESSE, Orlando \& DE MEDEIROS, Paulo. (orgs.). A Companion to João Paulo Borges Coelho. (Re)Writing the (Post)Colonial Remains. London: Peter Lang, 2020. (no prelo)

CAN, Nazir Ahmed. Discurso e poder nos romances de João Paulo Borges Coelho. Maputo: Alcance Editores, 2014.

GINZBURG, Carlo. Olhos de Madeira. São Paulo: Companhia das Letras, 2001 [1998].

GINZBURG, Carlo. Mitos, Emblemas, Sinais: Morfologia e História. São Paulo: Companhia das Letras, 1989.

KHAN, Sheila. et al. (orgs.). Visitas a João Paulo Borges Coelho: leituras, diálogos e futuros. Lisboa: Edições Colibri, 2017.

LACOSTE, Yves. A geografia - isso serve, em primeiro lugar, para fazer a guerra. Campinas: Papirus, 1988 [1976].

MORETTI, Franco. Conjectures on world literature. New left review 1, 2000, pp. 54-68. 
PEARSON, Michael N. The Indian Ocean. London: Routledge, 2007.

ROUSSEL, Raymond. Impressions d'Afrique. Paris: Flammarion, 2011 [1909].

ROUSSEL, Raymond . Nouvelles Impressions d'Afrique. Marseille: Al Dante, 2004 [1932].

SARLO, Beatriz. Sete ensaios sobre Walter Benjamin e um lampejo. Rio de Janeiro: Editora da UFRJ, 2013 [2000]. TORABULLY, Khal. Chair corail, fragments coolies: poésie. Matoury: Ibis rouge, 1999.

WALLERSTEIN, Immanuel. The modern world-system: Capitalist agriculture and the origins of the European world-economy in the sixteenth century. New York and London: Academic Press, 1974.

WALLERSTEIN, Immanuel. The modern world-system II: Mercantilism and the consolidation of the European world-economy, 1600-1750. New York: Academic Press, 1980. WALLERSTEIN, Immanuel. The modern world-system III: The second era of great expansion of the capitalist world-economy, 1730-1840s. San Diego, London, Boston, New York, Sydney, Tokyo and Toronto: Academic Press, 1989. WREC. Combined and Uneven Development: Towards a New Theory of World-Literature. Liverpool: Liverpool University Press, 2015.

WREC, Desenvolvimento Combinado e Desigual: Por uma Nova Teoria da Literatura-Mundial. Organização de Elena Brugioni, Alfredo Cesar Melo e Paylo de Medeiros. Tradução de Gabriela Beduschi Zanfelice. Campinas: Editora Unicamp, 2020 (no prelo). 